GU J Sci, Part C, 5(4): 187-199 (2017)

Gazi Üniversitesi
Fen Bilimleri Dergisi
PART C: TASARIM VE TEKNOLOJI
dergipark.gov.tr/http-gujsc-gazi-edu-tr

\title{
Güç Kaynakları İçin Yüksek Verimli Güç Faktörü Düzeltme Devresi Tasarımı
}

\author{
Ali Osman ÇINAR, Atiye Hülya OBDAN* \\ Yıldız Teknik Üniversitesi Üniversitesi, Elektrik- Elektronik Fakültesi, Elektrik Mühendisliği Bölümü, 34220, \\ Esenler/ISTANBUL
}

\begin{abstract}
$\ddot{O} z$
Makale Bilgisi

Başvuru: 09/11/2017

Düzeltme: 14/12/2017

Kabul: 14/12/2017

\section{Anahtar Kelimeler}

Anahtarlamalı güç kaynakları için güç faktörü düzeltme devreleri tasarlamak enerjinin verimli kullanılabilmesi açısından son yıllarda önemli hale gelmiştir. Güç faktörü düzeltme (GFD) teknikleri, yüksek güç yoğunluğu ve enerji verimliliği açısından çok önemli bir rol oynamaktadır. $\mathrm{Bu}$ amaçla temel yükseltici GFD devrelerinin yanında, köprüsüz GFD topolojileri ve kontrol stratejileri geliştirilmiştir. Köprüsüz yapılar kullanılarak, devredeki kayıplar azaltılarak güç yoğunluğu arttırılabilir. Bu makalede, köprüsüz GFD yapıları incelenerek, kayıplar ve güç faktörü açısından performansları karşılaştırılmıştır. Yüksek güç seviyelerinde yaygın bir şekilde kullanılan yarı köprü çift yükseltici yapılı GFD devresi analiz edilmiş ve akım modlu kontrol yöntemi uygulanarak tasarlanan devrenin benzetimi PSIM programında yapılmıştır. $900 \mathrm{~W}$ ' lık yarı köprü çift yükseltici yapılı GFD devresinin bir prototipi gerçekleştirilmiş ve devreden elde edilen sonuçlar sunulmuştur.
\end{abstract}

Güç faktörü düzeltme (GFD), Köprüsüz Güç Faktörü Düzeltme (KGFD), Sürekli Iletim Modu (SIM), Ortalama Akım Modlu Kontrol, Yart Köprü çift yükseltici yapılı GFD Topolojisi

\section{Keywords}

Power Factor Correction (PFC), Bridgeless Power Factor Correction (BPFC), Continuous Conduction Mode (CCM), Average Current Mode Control (ACM), Semi Bridgeless PFC (SBPFC) Topology

\section{Design of The High Efficiency Power Factor Correction Circuit for Power Supply}

\begin{abstract}
Designing power factor correction circuits for switched power supplies has become important in recent years in terms of efficient use of energy. Power factor correction techniques play a significant role in high power density and energy efficiency. For these purposes, bridgeless PFC topologies and control strategies have been developed alongside basic boost PFC circuits. The power density can be increased using bridgeless structures by means of reducing losses in the circuit. This article examines bridgeless PFC structures and compares their performances in terms of losses and power factor. A semi-bridgeless PFC, which is widely used at high power levels, was analyzed and simulated. The designed circuit simulation using the current mode control method was performed in the PSIM program. A prototype of a $900 \mathrm{~W}$ semi-bridgeless PFC circuit was implemented and the results obtained from the circuit are presented.
\end{abstract}

\section{GİRIŞ̧ (INTRODUCTION)}

Teknolojinin gelişimi ile birlikte günümüzde her alanında ihtiyaç duyulan elektrikli cihazlar çok daha fazla tüketilmekte ve bunun sonucu olarak enerjinin verimli kullanılması ön plana çıkmaktadır. Yarı iletken teknolojisi kullanılan güç elektroniği devreleri hemen hemen her elektrikli cihazın yapısında bulunmakta ve bu lineer olmayan yüklerin şebekeden çektiği harmonikli akım ve gerilimler enerji kalitesinin azalmasına sebep olmaktadır [1].

Enerjinin verim ve kalitesi açısından, harmonikli akımların şebekeye olumsuz etkilerini önlemek ve güç faktörü için, çeşitli standartlar getirilmiştir. Bu standartları sağlayabilmek ve cihazların verim ve kalitesini arttırabilmek için güç faktörü düzeltme (GFD) teknikleri geliştirilmiştir. Güç Faktörü düzeltme (GFD) devresinin temel amacı aktif gücün görünen güce oranı olan güç faktörünü (GF) 1'e yaklaştırmaktır. AC 
giriş hattındaki harmonik akımlar sistemin GF performansını bozar [2]. GF' deki bu bozulma için, elektrikli cihazların Avrupa Normu EN61000-3-2' ye uyması talep edilmektedir.

Anahtarlamalı güç kaynakları için güç faktörü düzeltme devreleri tasarlamak enerjinin verimli kullanılması için son yıllarda önemli hale gelmiştir. Bu amaçla birçok topoloji ve kontrol tekniği geliştirilmiştir. Bazı avantajlarından dolayı, yükseltici topolojisi birçok GFD uygulamasında yaygın olarak kullanılmaktadır. Yükseltici topolojisi ile endüktansın akımına bağlı olarak kesintili iletim modu (KİM), sınırda çalışma modu (SÇM) ve sürekli iletim modunda (SİM) çalışma sağlanabilir. Birçok tasarımda 300 W' in altındaki güç değerleri için KİM ve SÇM çalışma kullanılırken, yüksek güç seviyesindeki uygulamalarda daha az akım dalgalanması ile daha fazla akım sağladığı için SìM çalışma kullanılır.

Bununla birlikte, yüksek güçlü uygulamalar için güç faktörü düzeltme devresi tasarlanırken kayıplar önem kazanmaktadır. Bu durum, tasarımcıları güç devrelerinde kayıpların azaltılması için çözümler üretmeye yönlendirmiştir. Şekil 1' deki geleneksel GFD devresinde EMI filtresi ve GFD katı arasına yerleştirilen köprü diyotları görülmektedir.

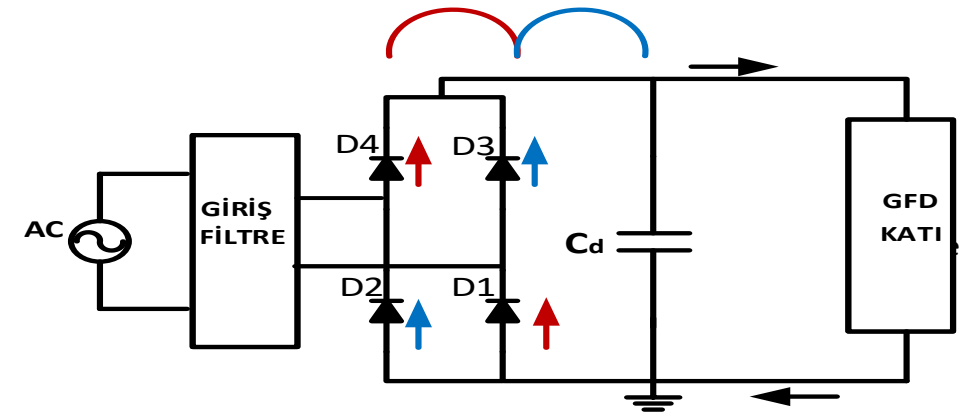

Şekil 1. Geleneksel tam köprülü GFD devre şeması (Traditional full bridge GFD circuit diagram)

Artan güç ihtiyacı ile birlikte devrelerin verimi de büyük bir önem kazanmaya başlamıştır. Şekil 1' de geleneksel tam köprülü yükseltici GFD devresi gösterilmiştir. Giriş gerilimi diyot köprüsü ile doğrultularak GFD katına aktarılır. Bu esnada yarım şebeke periyodu boyunca aynı anda iki diyot iletimde olmaktadır. Diyotların üzerindeki iletim gerilim düşümü enerji kayıplarını oluşturmaktadır. Dolayısı ile bir şebeke yarım periyodu içerisinde giriş akımının ortalama değeri bir diyot üzerinden geçmektedir. Buna göre

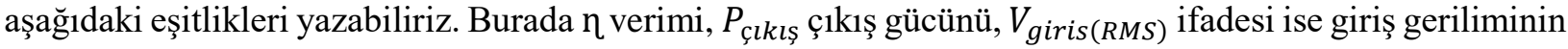
efektif değerini temsil etmektedir.

$$
l_{\text {giris }(R M S)}=\frac{P_{c ̧ \iota k l s}}{\eta \cdot V_{\text {giris }(R M S)}}
$$

Aynı anda iki diyot sürekli olarak giriş akımının ortalama değerini gördüğünden, (1) kullanılarak köprünün güç kaybı denklem (2) deki gibi hesaplanır. Burada $V_{D}$ ifadesi bir diyotun üzerindeki iletim gerilim düşümünü ifade eder.

$$
P_{k o ̈ p r u ̈ ~}=2 \cdot V_{D} \cdot \frac{2 \cdot \sqrt{2} \cdot P_{c ̧ \iota k l s ̧}}{\eta \cdot V_{\text {giris }(R M S)} \cdot \pi}
$$

Özellikle GFD devrelerinde kayıplara sebep olan elemanlar incelendiğinde, diyot köprüsündeki diyotlarda (2) de görüldüğü gibi ciddi kayıpların oluştuğu görülmektedir. Bu kapsamda köprüsüz GFD çözümleri geliştirilmiştir.[3] Klasik köprüsüz GFD devrelerinin yanısıra, daha yüksek güçlerde kullanılmak üzere geliştirilen, klasik köprüsüz yapıdan türetilmiş farklı güç kademelerinde kullanılan yapılar mevcuttur. Sunulan çalışmada Köprüsüz GFD topolojilerinden yaygın bir şekilde kullanılan yarı köprü çift yükseltici yapılı GFD devresi analiz edilmiştir. Akım modlu kontrol yöntemi uygulanan devrenin benzetimi PSIM programında yapılarak, $900 \mathrm{~W}$ çıkış gücü ve $400 \mathrm{~V}$ çıkış geriliminde bir prototip kurularak deneysel sonuçlar alınmıştır. Deneysel sonuçlardan görüleceği gibi sistem $900 \mathrm{~W}$ 'a kadar olan güçlerde yüksek verimle ve yüksek güç faktörüyle çalışmıştır. 


\section{KÖPRÜSÜZ GFD TOPOLOJILERİ (BRIDGELESS PFC TOPOLOGIES)}

Şekil 2' de geleneksel köprüsüz GFD devresi gösterilmektedir. Şekildeki iki anahtarlama hücresinde Q1 ve Q2 mosfetleri, D1 ve D2 ise diyotları göstermektedir. P1 noktasının potansiyeli P2 noktasına göre yüksek olduğunda Q1 iletimde olduğunda L endüktans1 enerji depolar, Q1 kesimde olduğunda L endüktansinda depolanan enerji D1 diyotu üzerinden çıkışa aktarılır. Q1 anahtarının kesim ve iletim anlarındaki devreden akan akımın dönüşü ise Q2 mosfetinin dahili diyotu üzerinden kaynağa doğru olur. Aynı çalışma durumu diğer şebeke yarım periyodunda, P2 noktasının potansiyeli P1' den büyük olduğu zaman, Q2 anahtarı, D2 diyotu ve Q1 mosfetinin dahili diyotu üzerinden gerçekleşir.

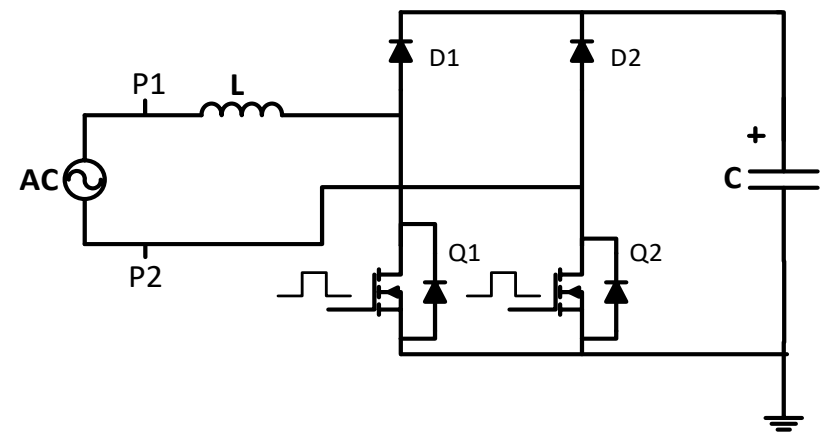

\section{Şekil 2. Geleneksel köprüsüz GFD devre şeması (Traditional bridgeless PFC circuit diagram)}

Şekil 2' deki devrenin verim açısından avantajları olsa da, kaynağın referansının GFD katııın referansına göre dengesiz olması ve bobin akımının kolay bir şekilde algılanamaması gibi dezavantajları vardır. Aynı zamanda devre uygulamasında EMI filtreleme çok ciddi bir problem oluşturmaktadır. Öyle ki P1 noktası pozitif olduğunda negatif P2 noktası Q2 mosfetinin dahili diyotu üzerinden kaynağın referansına bağlanır. Sonuç olarak GFD katının referansı geleneksel köprülü GFD devrelerinde olduğu gibi kaynak referansı ile aynı olur. P2 noktası pozitif olduğunda Q2 mosfeti anahtarlanır ve kaynak uçlarındaki gerilim ile GFD katının referansı dalgalanır. Yani P2 noktasının potansiyeli 0 ile GFD katının çıkış voltajı arasında dalgalanır. Bu büyük değerdeki gerilim yükselme hızı $(\mathrm{dV} / \mathrm{dt})$ filtre edilmesi zor olan ortak mod gürültüsüne sebep olur. Bu sebeple farklı yapılarda köprüsüz GFD devreleri geliştirilmiştir [4], [5].

Şekil 3a ve Şekil 3b' de, geleneksel yapıya iki diyot eklenerek oluşturulan köprüsüz GFD devre yapılanı görülmektedir. Buna ek olarak, Şekil 3b' deki yapıda çift yönlü anahtar kullanılmaktadır ve Q1 ve Q2 mosfetlerinin ortak kaynak noktası çıkış geriliminin referans noktasından ayrıdır [6], [7]. Aynı zamanda D1 ve D3 diyotları hızlı toparlanmalı (fast-recovery) ve D4 ve D2 diyotları ise yavaş toparlanmalı (slowrecovery) diyotlardır. Şebekenin pozitif yarım dalgasında AC kaynak D4 diyotu üzerinden çıkış referansına bağlanırken, negatif yarım dalgasında AC kaynak D2 diyotu üzerinden çıkışın pozitif noktasına göre bağlanır.

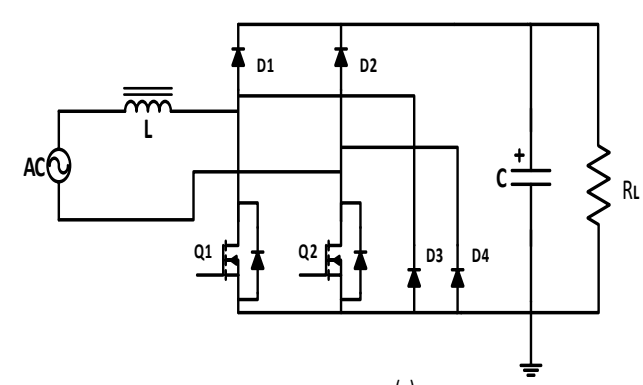

(a)

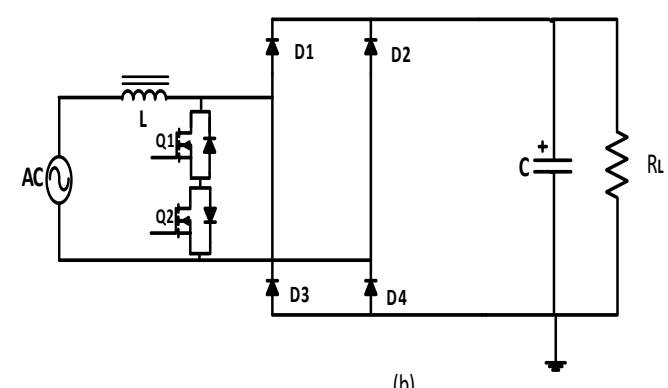

(b)

Şekil 3. (a) Geleneksel köprüsüz yapıdan elde edilen yarım köprü GFD yapısı (b) Çift yönlü anahtar kullanarak oluşturulan GFD yapisi( (a) Half bridge PFC structure obtained from classical bridgeless structure (b) Bridgeless PFC structure with bidirectional switch) 


\section{YARI KÖPRÜ ÇIFT YÜKSELTICI YAPILI GFD DEVRESİ (SEMI BRIDGELESS PFC CIRCUIT)}

Şekil 4' de Yarı köprü çift yükseltici yapılı GFD devre şeması gösterilmektedir. Bu devrenin köprüsüz GFD devrelerinden farkı GFD katının referansının giriş hattının referansına D3 ve D4 diyotu üzerinden bağlı olmasıdır. Bu sayede tam köprüsüz GFD devresindeki ortak mod gürültüsü bu devrede yok edilmiş olur. Fakat iki diyot olmasından ötürü köprü kayıpları azda olsa devam etmektedir. Bu yapıda iki endüktans bulunmakta ve şebekenin birinci yarım periyodunda biri enerji depolayıp çıkışa aktarırken şebekenin ikinci yarım periyodunda diğer endüktans enerji depolayıp çıkışa aktarma görevini sürdürür, aynı zamanda devredeki D1 ve D2 diyotları hızlı toparlanan, D3 ve D4 diyotları yavaş toparlanan diyotlardır [8].

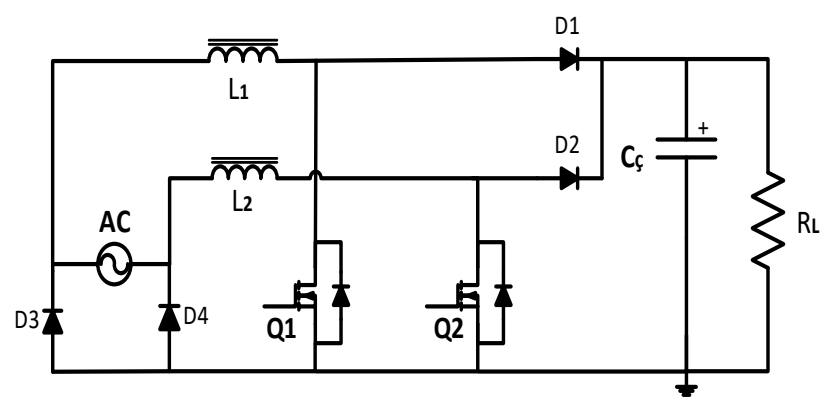

Şekil 4. Yarı köprü çift yükseltici yapılı GFD topolojisi (Semi bridgeless PFC topology)

$\mathrm{Bu}$ topoloji ile yarı iletken elemanlar ve endüktans üzerinde oluşan enerji kayıları, geleneksel GFD devreleri kıyaslandığında, yarıya düşmektedir. Ayrıca girişteki doğrultucu diyotlarının sayısı ikiye düşürüldüğü için, bir şebeke alternansında sadece bir doğrultucu diyotu aktif olmaktadır. Bunların sonucunda devrenin verimi ciddi oranda iyileşmektedir. Bir diğer açıdan, bu yapıda bir şebeke periyodu boyunca anahtarlama elemanının içinden geçen akımın efektif değeri düştüğü için,aynı güç seviyesi için, klasik GFD devrelerinde çıkamadığımız anahtarlama frekanslarına aynı anahtarlama elemanı ile çıkabilmekteyiz (MOSFET). Tablo 1' de yarı köprü ve tam köprülü klasik GFD yapılarında elemanlar içerisinden akan akımların efektif değerlerini belirten denklemler karşılaştırmalı olarak verilmiştir. Devre verim açısından ciddi bir avantaj sağlasada, aynı güç seviyesi için klasik yükseltici GFD yapılarına nazaran, iki katı bobin ve anahtarlama elemanı gerektirdiğinden maliyet açısından dezavantajlıdır. Ancak yeni nesil TV' lerde kullanılan yüksek güç yoğunluğu gereksinimini sağlayan güç kaynakları için oldukça avantajlidir.

Tablo 1. Geleneksel tam köprü SIMM yükseltici GFD devresi ile yarı köprü çift yükseltici yapılı SìM yükseltici GFD devresi elemanların akımların karşılaştırllması (A comparison of currents flowing through traditional full bridge CCM boost PFC and semi-bridgeless CCM boost PFC circuits )

\begin{tabular}{|c|c|c|c|}
\hline & $\begin{array}{l}\text { Geleneksel köprüsüz (SİM) } \\
\text { GFD devresi }\end{array}$ & $\begin{array}{l}\text { Yarı köprü çift yükseltici yapılı } \\
\text { (SİM) GFD devresi }\end{array}$ & Akımların oranları \\
\hline $\begin{array}{l}\text { Bir şebeke periyodu } \\
\text { boyunca anahtarlama } \\
\text { elemanı akımı efektif } \\
\text { değeri(rms) }\end{array}$ & $\frac{P_{c ̧ l k l s}}{V_{\text {giriş } \min } \cdot \eta} \cdot \sqrt{1-8 \sqrt{2} \cdot \frac{V_{\text {giris__n }}}{3 \pi \cdot V_{c l}}}$ & 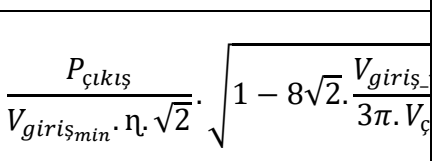 & 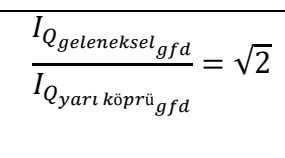 \\
\hline $\begin{array}{lr}\text { Bir şebeke } & \text { periyodu } \\
\text { boyunca çıkış } & \text { diyotu } \\
\text { akımı } & \text { efektif } \\
\text { değeri(rms) } & \end{array}$ & $\frac{P_{c ̧ l k l s}}{V_{\text {girişmin }} \cdot \eta} \cdot \sqrt{8 \sqrt{2} \cdot \frac{V_{\text {giriș_min }}}{3 \pi \cdot V_{c ̧ \iota k l s}}}$ & $\frac{P_{c ̧ l k l s ̧}}{V_{\text {girișin }} \cdot \eta \cdot \sqrt{2}} \cdot \sqrt{8 \sqrt{2} \cdot \frac{V_{\text {giriș_min }}}{3 \pi \cdot V_{\text {çlkls }}}}$ & 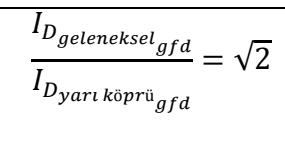 \\
\hline $\begin{array}{lr}\text { Bir şebeke } & \text { periyodu } \\
\text { boyunca } & \text { endüktans } \\
\text { akımı } & \text { efektif } \\
\text { değeri(rms) } & \end{array}$ & $\frac{P_{c ̧ l k l s ̧}}{V_{\text {girișin }} \cdot \eta}$ & $\frac{P_{c ̧ l k l s ̧}}{V_{\text {giris }_{\text {min }} \cdot \eta \cdot \sqrt{2}}}$ & $\frac{I_{L_{\text {geleneksel }}}}{I_{L_{\text {yarl } k \text { köprü }}}}=\sqrt{2}$ \\
\hline
\end{tabular}




\subsection{Yarı Köprü Çift Yükseltici Yapılı GFD Devresinin Çalışma Prensibi (Operation Principle Of Semi Bridgeless PFC Circuit)}

Şekil 5' de yarı köprü çift yükseltici yapılı GFD devresinin çalışma aralıkları görülmektedir. P1 pozitif P2 negatif olduğunda Q1 mosfeti iletimde iken, birinci GFD katı endüktans1 enerji depolar. Q1 kesimde iken endüktansta depolanan enerji D1 diyotu üzerinden çıkışa aktarılır. Bu sırada akım devredeki yolunu Q2 mosfetinin dahili diyotu ve D4 diyotu üzerinden tamamlayarak kaynağa döner. Aynı şekilde P2 pozitif P1 negatif olduğunda Q2 mosfeti iletimde iken, ikinci GFD kat1 endüktans1 enerji depolar. Q2 mosfeti kesimde iken endüktansta depolanan enerji D2 diyotu üzerinden çıkışa aktarılır. Bu sırada akım devredeki yolunu Q1 mosfetinin dahili diyotu ve D3 diyotu üzerinden tamamlayarak kaynağa döner [12-15].

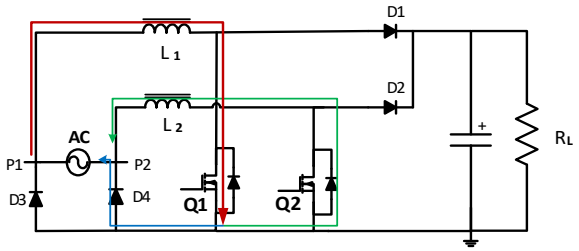

(a)

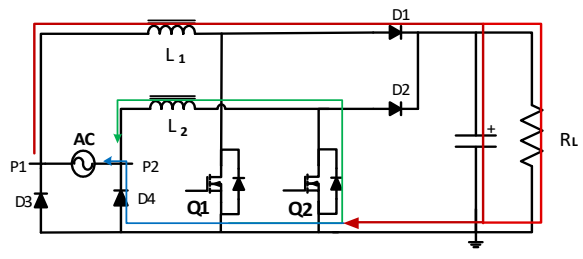

(b)

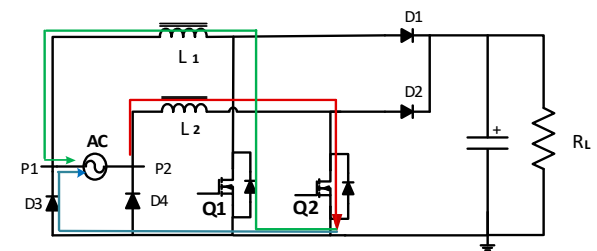

(c)

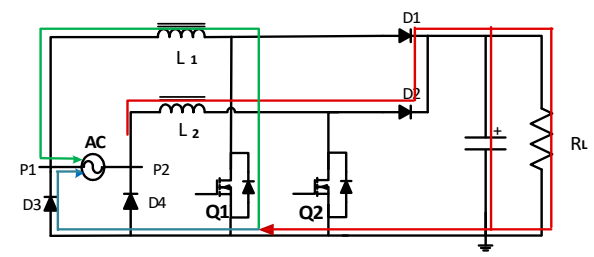

(d)

Şekil 5. Yarı köprü çift yükseltici yapılı GFD devresinin çalışma aralıkları (a) Q1 iletimde, (b) Q1 kesimde, (c) Q2 iletimde, (d) Q2 kesimde (Operating modes of the semi-bridgeless PFC circuit (a) Q1 turn on, (b) Q1 turn off, (c) Q2 turn on, (d) Q2 turn off)

\subsection{Yarı Köprü Çift Yükseltici Yapılı GFD Devresinin Tasarım Kriterleri (Design Criteria of Semi Bridgeless PFC Circuit)}

Yarı köprü çift yükseltici yapılı GFD topolojisinde, parallel bağlı iki yükseltici GFD katı bulunmaktadır. Bir yarım şebeke periyodunda birinci GFD katı aktif iken, diğer yarım şebeke periyodunda ikinci GFD katı aktif olmaktadır [16], [17]. Bu nedenle sadece bir GFD katında kullanılan endüktans değerinin hesaplanması yeterli olacaktır. Endüktans değerleri (3)' deki gibi hesaplanır.

$$
L_{1}=L_{2}=\frac{1}{\%_{\text {dalgalanma }}} \cdot \frac{V_{\text {giris__min }}^{2}}{P_{\text {çıkıs }}} \cdot\left(1-\sqrt{2} \cdot \frac{V_{\text {giris_min }}}{V_{\text {çikiş }}}\right) \cdot \frac{1}{f_{\text {anahtarlama }}}
$$

Giriş akımının ortalama değeri (4) kullanılanılarak köprü diyotlarının kayıpları (5) bulunur.

$$
\begin{aligned}
l_{\text {giriş_ort }} & =\frac{2}{\pi} \cdot \sqrt{2} \cdot \frac{P_{\text {çıklş }}}{V_{\text {giriș_min }} \cdot \eta} \\
P_{\text {köprü }} & =l_{\text {giriș_ort }} \cdot V_{f_{-} k \text { öprö }}
\end{aligned}
$$

Çıkış akımının ortalama değeri (6) kullanılanılarak, çıkış diyotu iletim güç kaybı (7) bulunur.

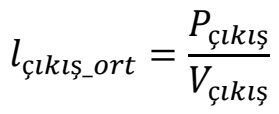

$$
\begin{aligned}
& P_{\text {diyot }}=l_{\text {çlkıs_ort }} . V_{f_{-} c ̧ \text { lk } l s ̧ d i y o t u}
\end{aligned}
$$

Çıkış kapasitesinin hesaplanması aşamasında ise şebekeden enerji kesildiği andan itibaren kapasitenin tutma zamanı $\left(t_{\text {tutma }}\right)$ boyunca enerji aktarımına göre hesap yapılarak, (8) deki gibi kapasite değeri bulunur. 


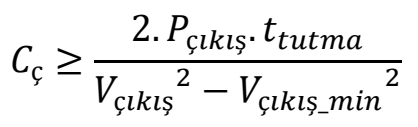

Mosfet efektif akımı denklem (9) dan hesaplanmıştır.

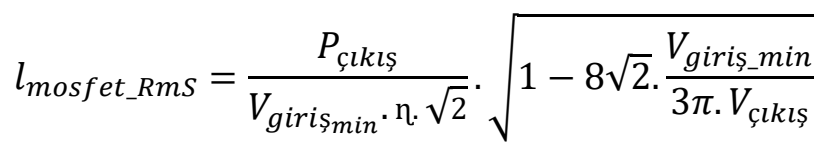

Yükseltici dönüştürücüde olduğu gibi burada da elemanlar maksimum olarak çıkış gerilimine maruz kalır. Bu nedenle $\left(Q_{1}\right.$ ve $\left.Q_{2}\right)$ mosfetleri ve $\left(D_{1}\right.$ ve $\left.D_{2}\right)$ çıkış diyotları çıkış geriliminden büyük olacak şekilde standart olarak seçilir.

Tasarım kriteri olarak giriş gerilim aralığı (140-275) V olarak alınmış olup en kötü koşulda bobin akımının dalgalanması $\% 25$, çıkış gerilimi $400 \mathrm{~V}$, çıkış gerilimindeki dalgalanma miktarı $10 \mathrm{~V}$ ve maksimum çıkış gücü $1000 \mathrm{~W}$ olarak belirlenmiştir. Anahtarlama frekans1 ise $200 \mathrm{kHz}$ olup bu kabuller çerçevesinde devrenin pasif elemanlarının, bobin endüktansı, çıkış kapasitesi değerleri ile mosfet ve diyot akımlarının efektif değerleri hesaplanmıştır.

\subsection{Yarı Köprü Çift Yükseltici Yapılı GFD Devresinin Benzetimi (Simulation of The Semi Bridgeless PFC Circuit)}

Benzetim devresinde kullanılan parametreler Tablo 2' de verilmiştir.

Tablo 2. Yarı köprü çift yükseltici yapılı GFD devresinin benzetim parametreleri (Simulation parameters of the semi bridgeless PFC circuit)

\begin{tabular}{|l|l|}
\hline Parametreler & Devrenin Çalışma Şartları ve Eleman Değerleri \\
\hline Giriş gerilimi aralığ $\left(\mathrm{V}_{\mathrm{g}}\right)$ & $(140-275) \mathrm{V}$ \\
\hline Çıkış gerilimi $\left(\mathrm{V}_{\mathrm{c}}\right)$ & $400 \mathrm{~V}$ \\
\hline Maksimum çıkış gücü $\left(\mathrm{P}_{\mathrm{ccm}}\right)$ & $1 \mathrm{~kW}$ \\
\hline Bobin Endüktansı $\left(\mathrm{L}_{1}, \mathrm{~L}_{2}\right)$ & $198 \mathrm{uH}$ \\
\hline Çıkış kapasitesi $\left(\mathrm{C}_{\mathrm{c}}\right)$ & $900 \mathrm{uF}$ \\
\hline Anahtarlama frekansı $\left(\mathrm{f}_{\mathrm{s}}\right)$ & $200 \mathrm{kHz}$ \\
\hline
\end{tabular}

Şekil 6, PSIM programında kurulan benzetim devre şemasını göstermektedir. Devrede ortalama akım modu kontrolü kullanılmıştır. Gerilim geri beslemesi için gerilim döngüsü ve akım geri beslemesi için akım döngüsü olmak üzere iki tip kontrol döngüsü içerir. Her bir anahtarı sürmek için iki ayrı akım kontrol döngüsü bloğu vardır. Burada $I_{r e f}$ sinyali, gerilim kontrol döngüsünün çıkışı ile doğrultulmuş giriş geriliminin örneklemesi çarpılarak elde edilir. Bu $I_{r e f}$ değeri akım kontrol döngüsüne referans akım değeri olarak girer ve akım kontrol döngüsünün çıkışı anahtarlama için gerekli doluluk oranını belirler. 


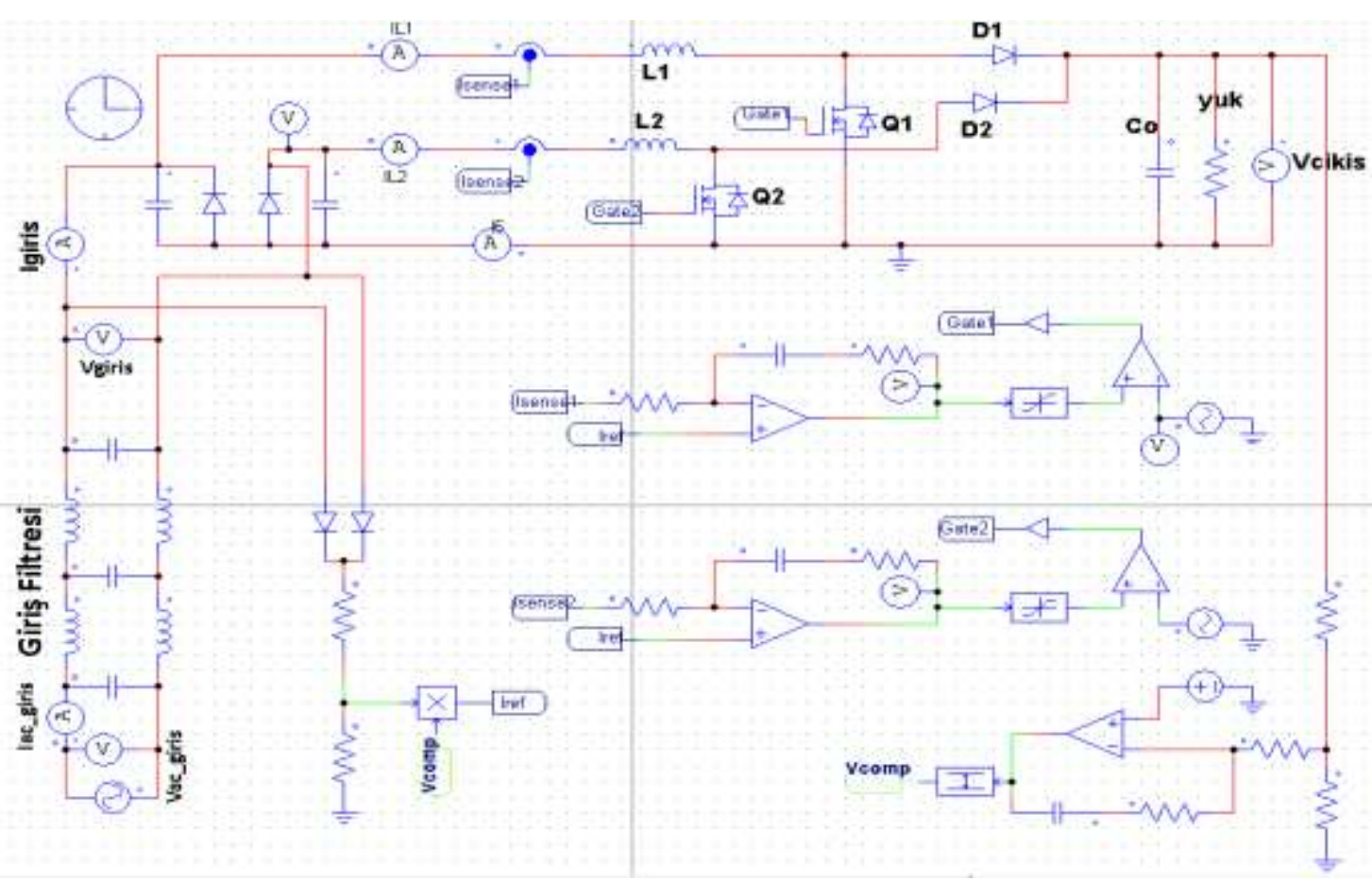

Şekil 6. Yarı köprü çift yükseltici yapılı GFD benzetim devre şeması (Semi bridgeless PFC simulation circuit diagram)

Şekil 7' de $Q_{1}$ ve $Q_{2}$ Mosfetlerinin kapı sinyalleri, Şekil 8' de sırasıyla $I_{L 1}$ ve $I_{L 2}$ endüktanslarının akım değişimleri görülmektedir. İlgili GFD katları pasif olduğunda akımın büyük kısmı mosfetlerin dahili diyotları üzerinden yolunu tamamlamaktadır.
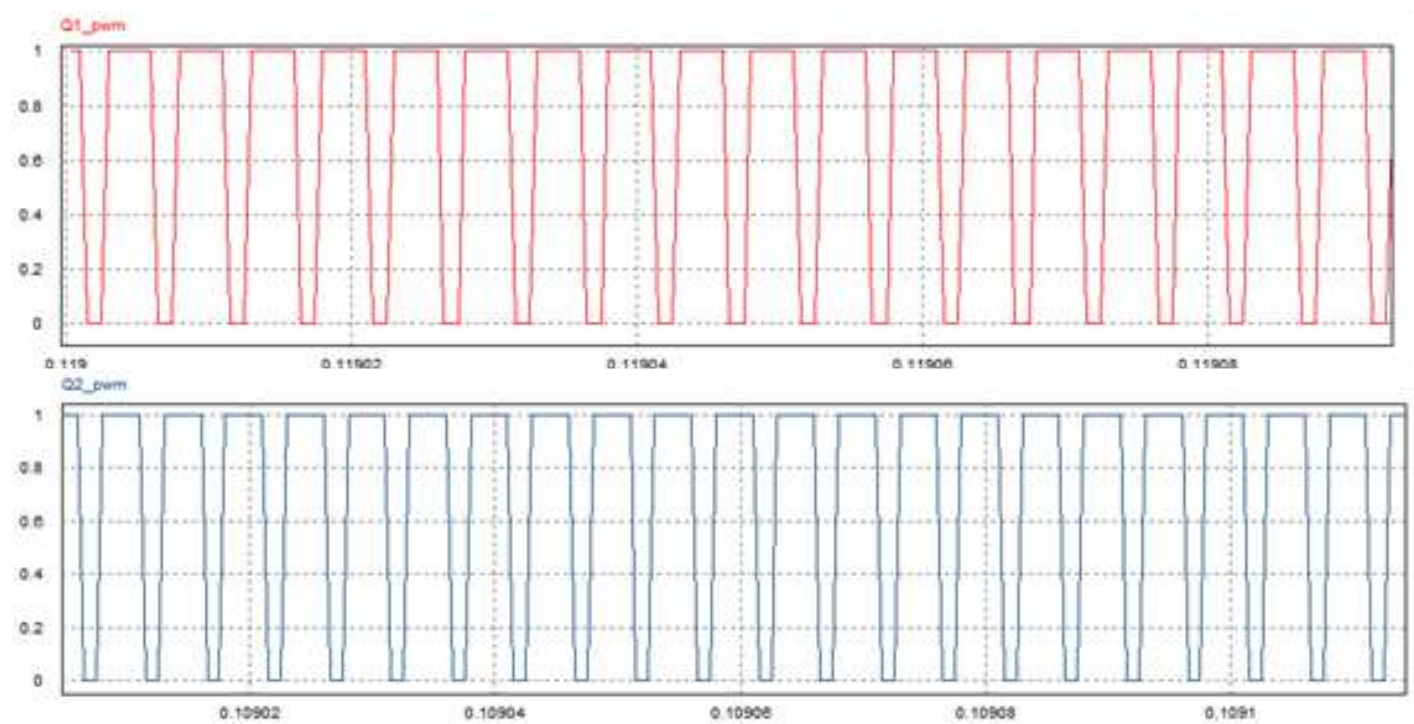

Şekil 7. $Q_{1}$ ve $Q_{2}$ mosfetlerine ait pwm sinyallerinin birkaç anahtarlama peryodundaki dalga şekilleri (The waveforms of the pwm signals of $Q_{1}$ and $Q_{2}$ mosfets in several switching periods) 


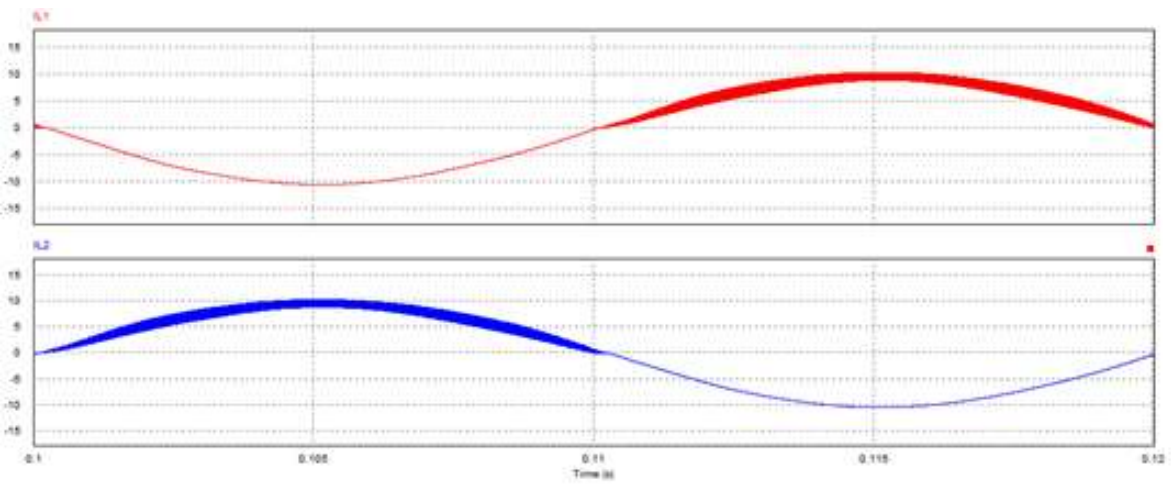

Şekil 8. $I_{L 1}$ ve $I_{L 2}$ endüktans akımlarının bir şebeke peryodu boyunca dalga şekilleri (The waveforms of $L_{1}$ and $L_{2}$ inductance currents over a network period)

Şebeke girişindeki filtre olmadan Şekil 9' da görüldüğü gibi giriş gerilim ve akımının değişiminden güç faktörü 0.997, giriş filtresi kullanıldığında ise Şekil 10' da görüldüğü gibi giriş gerilim ve akımının değişiminden güç faktörü 0,999 olarak bulunmuştur. Giriş filtresi akımdaki anahtarlama dalgalanmalarını sönümleyerek güç faktörü performansını da iyileştirmiş̧ir. Şekil 11' de ise çıkış geriliminin bir şebeke peryodu boyunca değişimi görülmektedir. Çıkış gerilimindeki dalgalanma şebeke frekansının iki katı bir frekansa sahiptir.

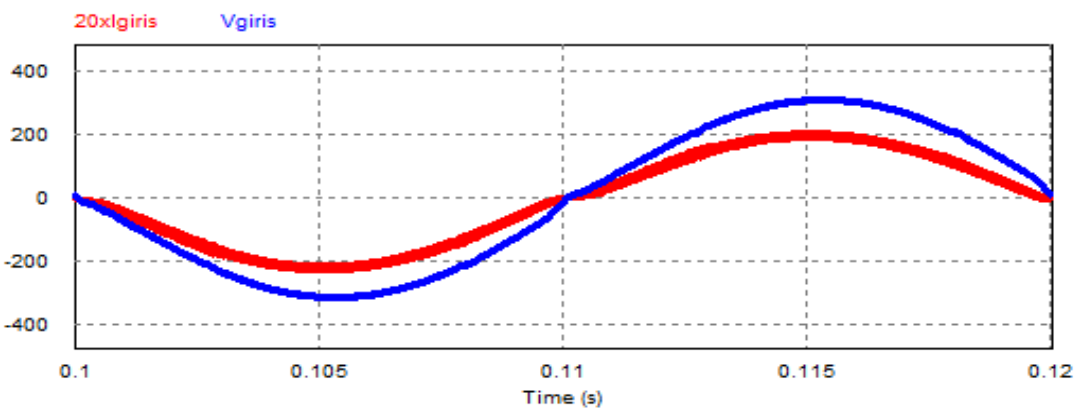

Şekil 9. Giriş filtresi öncesi, giriş gerilim ve 20*giriş akımı, güç faktörü (0.997) (Before input filter, input voltage and $20 *$ current, power factor (0.997))

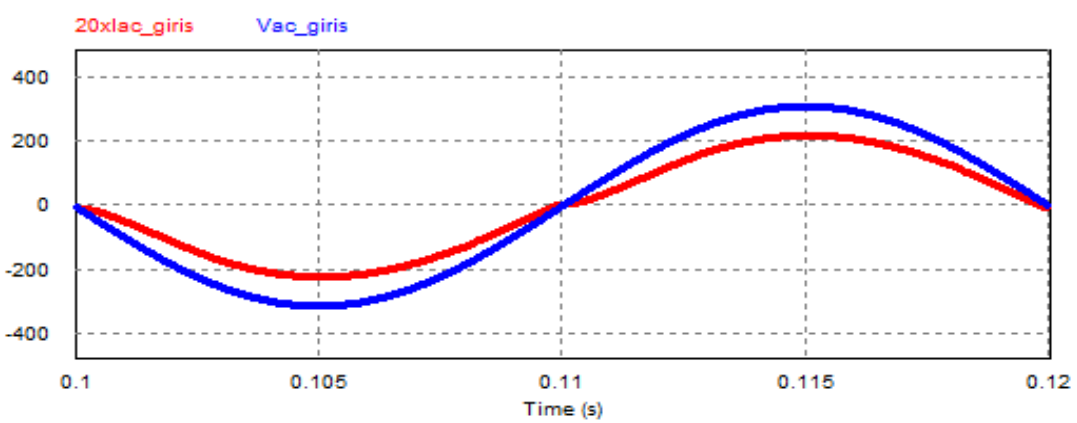

Şekil 10. Giriş filtresi sonrast, giriş gerilim ve 20xgiriş akımı, güç faktörü (0.999) (After input filter, input voltage and $20 *$ current, power factor (0.999)) 


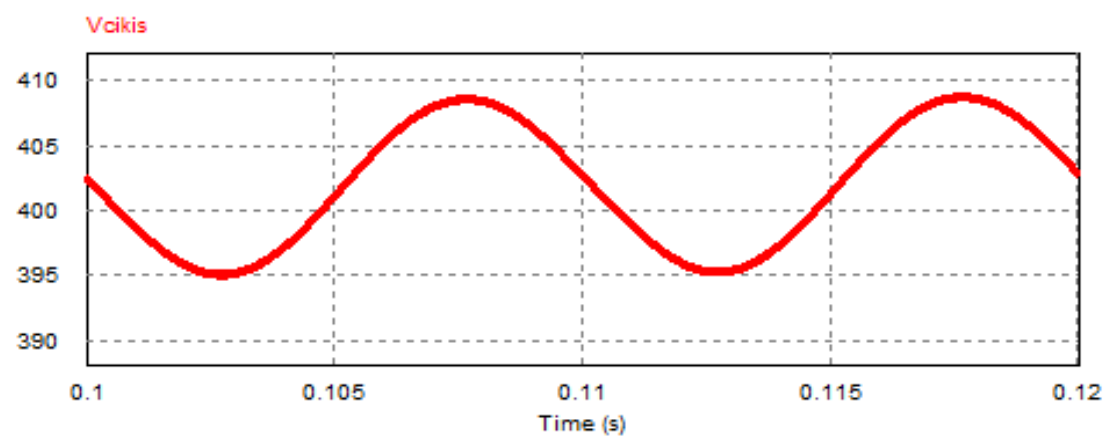

Şekil 11. Bir şebeke peryodu süresince çıklş geriliminin dalga şekli (The output voltage waveform over a network period)

\subsection{DENEYSEL SONUÇLAR (EXPERIMENTAL RESULTS)}

Sunulan devrenin 900 W' lık bir prototipi oluşturulmuştur. GFD katında kullanılan her bir endüktans değeri denklem (3)' den, çıkış kapasitesi değeri denklem (8)' den hesaplanmıştır. Mosfetler ve çıkış diyotları standart olarak $650 \mathrm{~V}$ ' luk seçilmiştir. Her bir şebeke alternansında bir GFD katı aktif olmaktadır ve endüktans akımı süreklidir. Devre, sürekli iletim modunda (SIM) çalışacak şekilde tasarlanmış ve ortalama akım modlu kontrol kullanılmıştır. Buna göre iki tane kontrol döngüsü bulunmaktadır. Çıkış kapasitesinden alınan gerilim geri beslemesi ile oluşturulan gerilim döngüsü çıkış gücünü ayarlar, akım döngüsü ise iç kontrol döngüsünü oluşturur. Bu kontrol yapısında endüktans akımının bir anahtarlama periyodu boyunca ortalaması alınarak bu değer gerilim döngüsünün oluşturduğu referans gerilimi ile hata yükselticisine verilerek PWM sinyalleri için kontrol gerilimi üretilmiş olur.

Pik akım modlu kontrole göre akım modlu kontrol yönteminin gürültülere karşı daha az hassas olması gibi bir avantajı mevcuttur. Ayrıca endüktans akımı sürekli ve dalgalanma azdır ve enerji aktarım kabiliyeti çok iyidir. Bu sebeple yüksek güçlerde SİM çalışma gereklidir [18], [19]. Avantajların yanı sıra diyot ve mosfetler sert bir şekilde iletime ve kesime girdiği için anahtarlama kayıplarının artması ve çıkış diyotunun ters toparlanma akımının yüksek olması gibi dezavantajları bulunmaktadır. Bu durum hem termal problemlere yol açarken, hem de gürültüye sebep olur. Bu nedenle ters toparlanma akımları çok az olduğu için tasarlanan devrede silicon carbide malzemesinden üretilen diyot kullanılmıştır.

Tablo 3. Yarı köprü çift yükseltici yapılı GFD devresinin prototipinde kullanılan elemanlar (Components used in the prototype of the semi bridgeless PFC circuit)

\begin{tabular}{|l|l|}
\hline Deneysel Devrede Kullanılan Elemanlar & Değerleri \\
\hline Endüktans $\left(L_{1}\right.$ ve $\left.L_{2}\right)$ & $170 \mathrm{uH}$ \\
\hline Çıkış kapasitesi $\left(C_{C}\right)$ & $940 \mathrm{uF}$ \\
\hline Mosfet $\left(Q_{1}\right.$ ve $\left.Q_{2}\right)$ & $650 \mathrm{~V} \mathrm{Si}$ \\
\hline Çıkış diyotu $\left(D_{1}\right.$ ve $\left.D_{2}\right)$ & $650 \mathrm{~V}$ hızlı silicon carbide $(\mathrm{SiC})$ \\
\hline
\end{tabular}

$220 \mathrm{~V}$ efektif giriş gerilimi ve $50 \mathrm{~Hz}$ şebeke frekansında devreden ölçümler alınmıştır. Devredeki her iki endüktansa ait akımların değişimi Şekil 12' de gösterilmiştir. Şekil 13' de ise bir GFD katına ait endüktans akımı ile ilgili kata ait mosfetin kanal-kaynak gerilimi gösterilmektedir. 


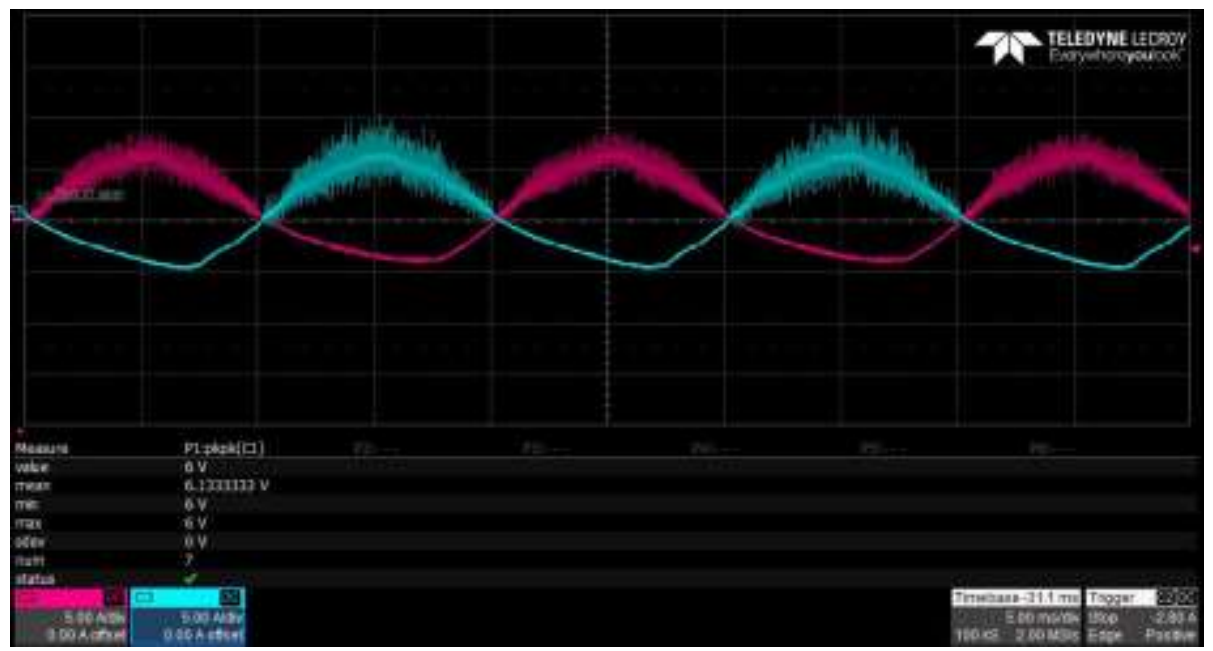

Şekil 12. $L_{1}$ ve $L_{2}$ endüktans akımlarının birkaç şebeke peryodu süresince dalga şekilleri (The waveforms of $L_{1}$ and $L_{2}$ inductance currents during several network periods)

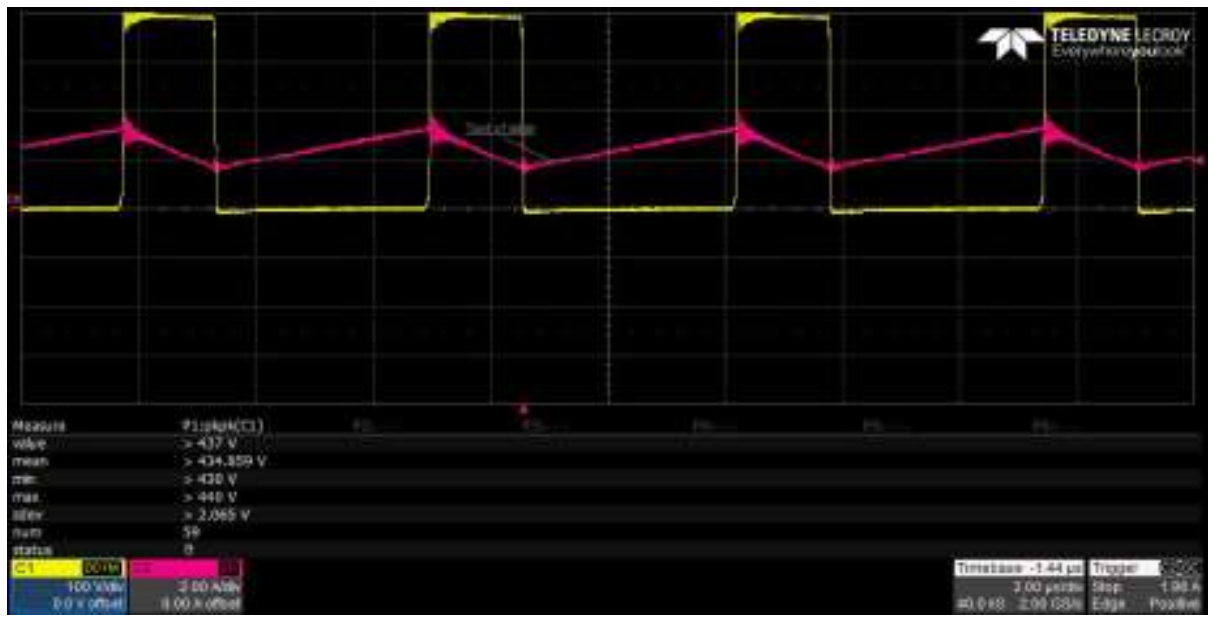

Şekil 13. Endüktans akımı ve mosfetin kanal-kaynak geriliminin birkaç anahtarlama peryodu süresince dalga şekilleri (Inductance current and mosfet channel-source voltage waveforms during several switching periods)

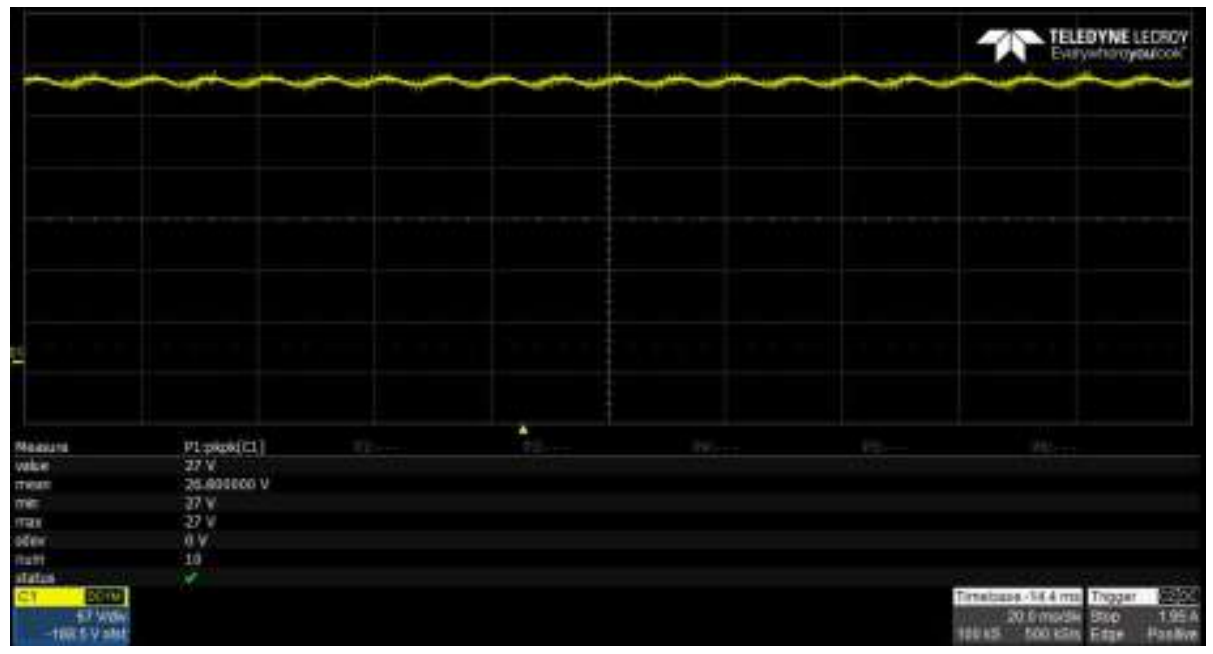

Şekil 14. Çıkış gerilimi dalga şekli (Output voltage waveform) 


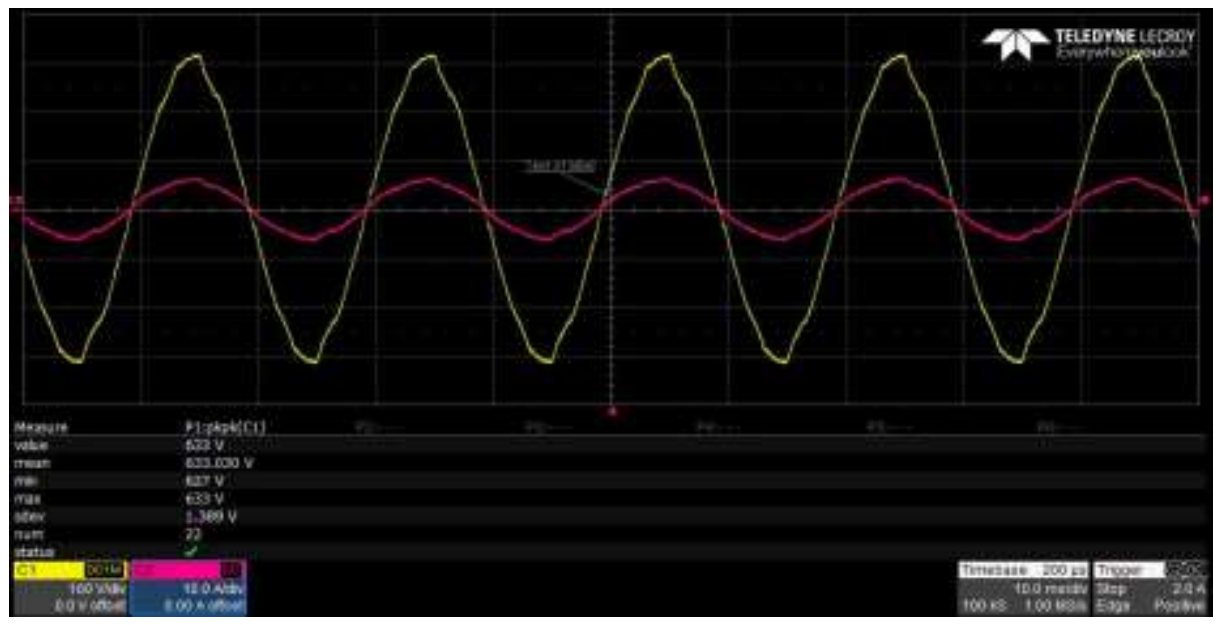

Şekil 15. Giriş gerilimi ve akımının birkaç şebeke peryodu boyunca dalga şekilleri (Input voltage and input current waveforms during several network periods)

Şekil 14' de çıkış gerilimi ve Şekil 15' de şebekeden çekilen akım ve geriliminin dalga şekli gösterilmektedir. Güç ölçümlerine dair elde edilen veriler ile çizilen verim ve güç faktörünün çıkış gücüne bağlı değişimleri Şekil 16 ve Şekil 17' de verilmiştir.

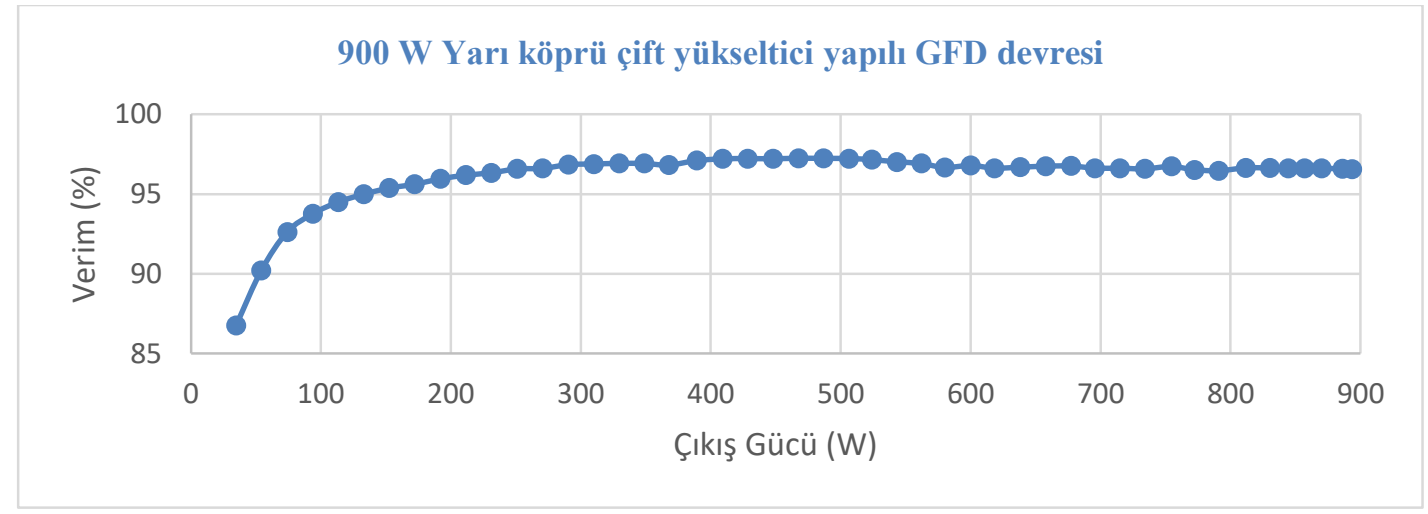

Şekil 16. Yarı köprü çift yükseltici yapılı GFD devresinin verim sonuçları (The efficiency results from semi bridgeless PFC circuit prototype)

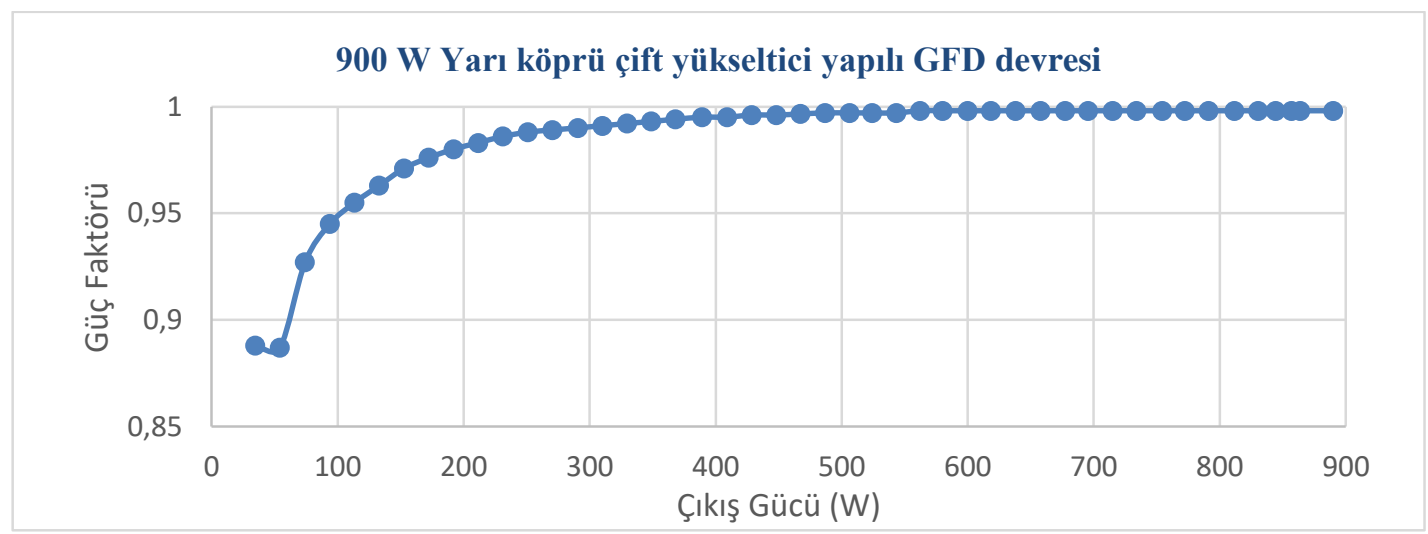

Şekil 17. Yarı köprü çift yükseltici yapılı GFD devresinin güç faktörü sonuçları (The power factor results from semi bridgeless PFC circuit prototype)

Ortalama akım modu kontrolü uygulanan yarı köprülü çift yükseltici yapılı PFC devresi, yüksek güç faktörü performansının yanında enerji aktarım kabiliyetinin mükemmelliği ve akımdaki dalgalanmanın az olması gibi avantajlara sahiptir. Ayrıca giriş akımındaki dalgalanma miktarı düşük olduğundan daha küçük değerli giriş filtresi kullanılabilmesine imkan sağlar. Şekil 16 ve 17' den, güç faktörü değerinin 0.998 ve verimin yaklaşık \%96.5 olduğu görülmektedir. 


\section{SONUÇ (CONCLUSION)}

Bu çalışmada, köprüsüz GFD devre topolojilerinin kısa bir karşılaştırması yapılarak, ortalama akım modu kontrolü ile çalışan Yarı köprülü GFD devresi analiz edilmiş, avantajları ve sınırlamaları verilmiştir. Devrenin benzetimi gerçekleştirilerek, 900 W' lik prototip oluşturulmuş ve deneysel sonuçlar sunulmuştur. Yarı köprülü GFD devresinin yüksek güç uygulamalarında verimlilik performansı, sadece iki köprü diyoduna sahip olması nedeniyle geleneksel GFD devrelerinden daha yüksektir. Bir diğer açıdan aynı güç seviyeleri için klasik yükseltici yapılı güç faktörü düzeltme devrelerinde yüksek anahtarlama frekanslarına çıkılamazken, sunulan yapıda bir şebeke periyodu boyunca anahtarlama elemanının içinden geçen akımın efektif değeri düştüğü için, aynı anahtarlama elemanı ile yüksek frekans değerlerine çıkılabilir. Çalışmada sunulan yapı klasik yükseltici GFD yapısı ile karşılaştırıldığında, bobin ve anahtarlama elemanı sayısının iki katına çıkması maliyeti arttırsa da verim açısından ciddi bir avantaj sağladığı için, yüksek güç yoğunluğu ve kompakt tasarım gerektiren TV güç kaynakları için uygun bir seçim olacaktır. Yapılan çalışmada yüksek güç yoğunluğu ihtiyacının olduğu uygulamalar için tasarlanan yarı köprülü GFD devresinin benzetim sonuçları ve deneysel sonuçlardan sistemin güç faktörü ve verim değerinin yüksek olduğu görülmüştür.

\section{TEŞEKKÜR (ACKNOWLEDGEMENTS)}

Bu çalışma üniversite ve sanayi işbirliği kapsamında Arçelik A.Ş. tarafından desteklenmiştir. Arçelik A.Ş.' ye katkılarından dolayı teşekkür ederiz.

\section{KAYNAKLAR (REFERENCES)}

[1] Rustom, K., Batarseh, I., "Recent advances in single stage power factor correction", In Industrial Technology, IEEE International Conference, Maribor, 1089-1095, 2003. DOI: 10.1109/ICIT.2003.1290815

[2] Kim, Y.S., Lee, B.K., L. J.W., "Topology characteristics analysis and performance comparison for optimal design of high efficiency PFC circuit for telecom", IEEE International Telecommunications Energy Conference (INTELEC), Amsterdam, 1-7, 2011. DOI: 10.1109/INTLEC.2011.6099764

[3] Huber, L., Jang, Y., Jovanovic, M.M., "Performance Evaluation of Bridgeless PFC Boost Rectifiers", IEEE Transactions on Power Electronics, 23 (3), $1381-\quad 1390,2008$. DOI: 10.1109/TPEL.2008.921107

[4] Kong, P., Wang, S., LEE, F.C., "Common Mode EMI Noise Suppression for Bridgeless PFC Converters", IEEE Transactions on Power Electronics, 23 (1), 291-297, 2008. DOI: 10.1109/TPEL.2007.911877

[5] Mahdavi, M., Farzanehfard, H., "New Bridgeless PFC Converter with Reduced Components," International Conference on Electronic Devices, Systems and Applications (ICEDSA), Kuala Kumpur, 125-130, 2011.

[6] Tollik, D., Pietkiewicz, A., "Comparative analysis of 1-phase active power factor correction topologies", International Telecommunication Energy Conference (INTELEC), Washington, 517-523, 1992. DOI: 10.1109/INTLEC.1992.268393

[7] Salmon, J.C., "Circuit topologies for PWM boost rectifiers operated from 1-phase and 3-phase ac supplies and using either single or split dc rail voltage outputs", IEEE Applied Power Electronics (APEC) Conference, Dallas, 473-479, 1995. DOI: 10.1109/APEC.1995.468990

[8] Gopinath, M., "Bridgeless PFC Converter for Power Factor Correction", International Journal of Advanced Engineering Sciences and Technologies, 9 (1), 49-54, 2011.

[9] Souza, A.F., Barbi, I., "High power factor rectifier with reduced conduction and commutation losses", International Telecommunication Energy Conference (INTELEC), Copenhagen 1999. DOI: 10.1109/INTLEC.1999.794044 
[10] Ernöand, T., Frisch, M.., "Second generation of PFC solutions”, Power Electronics Europe, 7, 33-35, 2004.

[11] Erickson, R.W., Maksimovic, D., "Fundamentals of Power Electronics", Kluwer, New York, 2001.

[12] Lai, J.S., Chen, D., "Design consideration for power factor correction boost converter operating at the boundary of continuous conduction mode and discontinuous conduction mode", Applied Power Electronics Conference, San Diego, 267-273, 1993. DOI: 10.1109/APEC.1993.290621

[13] Ucc28070 datasheet, Texas Instruments, Dallas, Texas, USA, 2016.

[14] Ucc28070 300W interleaved pfc pre-regulator user's guide-sluu321, Texas Instruments, Dallas, Texas, USA, 2008.

[15] Ucc28070 300W Interleaved Pfc Pre-Regulator Design Review-SLUA479 Application Report, Texas Instruments, Dallas, Texas, USA, 2016.

[16] O’Loughlin, M., “350W Two Phase Interleaved PFC Pre-regulator Design Review”, Texas Instrument Literature Number SLUA369 Application Report, Texas Instruments, Dallas, Texas, USA, 2006.

[17] Zumel, P., Garcia, O., Cobos, J.A., Uceda, J., "EMI Reduction by Interleaving of Power Converters", IEEE Applied Power Electronics Conference and Exposition, Anaheim, CA, USA, 688-694, 2004. DOI: 10.1109/APEC.2004.1295894

[18] O’Loughlin, M., “An Interleaving PFC Pre-Regulator For High-Power Converters", Unitrode/TI Power Supply Design Seminar SEM-1700, Topic 5, Texas Instruments, Dallas, Texas, USA, 2015.

[19] Choi, W.Y., Kwon, J. M., "Bridgeless dual-boost rectifier with reduced diode reverse-recovery problems for power-factor correction," IET Power Electronics, 1 (2), 194-202, 2008. 